\title{
What the Saskatchewan Roughriders Have Taught Me about Pharmacy
}

\author{
Jason Howorko
}

$\mathrm{T}$ The Saskatchewan Roughriders are my favourite team in the Canadian Football League. Last November, I watched my Riders lose to the Montréal Alouettes in the Grey Cup championship, in what I describe as the most exciting football game I've seen in my life.

The Riders lost the championship by a single point on the last play of the game. Just moments before that play was made, the players and thousands of fans thought Saskatchewan had won the game. Unfortunately, because of a Saskatchewan penalty for having too many players on the field, the Montréal players had one more opportunity to kick the winning field-goal $\ldots$ and they capitalized on it.

As I've reflected on all the events of the Riders' past, I've realized that there are several parallels with our profession.

Dream Big: Every year, we Saskatchewan fans (known as the "Rider Nation") maintain our optimism, believing in and supporting our team. No matter how badly our team may be playing, we continue to believe that our time as Grey Cup champions will come. Not long ago, the idea of prescribing by pharmacists seemed impossible, but today, advances in pharmacist practice, including prescribing, are progressing across the country.

Vision and Leadership: A long-term vision (which for our profession is exemplified by CSHP 2015 and the Blueprint for Pharmacy) is just as important for pharmacy as coaching and a playbook are to the Roughriders.

Teamwork: The quarterback on a football team needs excellent supporting players to achieve the team's goals. In health care, each of us makes a unique, valuable contribution and by working together as a team, we can have a significant impact on patient care.

Communication: In football, it is important to know what is going on, both on and off the field. In pharmacist practice, information and good communication are crucial to providing proper care. Poor communication is costly.

Accountability: Last fall, the Riders coach immediately took responsibility for losing the Grey Cup game. Even though many fans were "looking for blood", the coach's actions calmed us down and reinstated our faith in the team. Similarly, in pharmacist practice, we must all take responsibility for our actions. This attitude helps to ensure that we maintain the respect of our patients and other health care professionals.

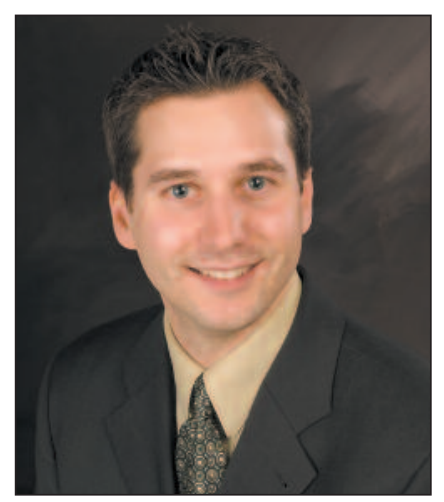

Little Plays Make a

Difference: Whether it is conceding a single point in a football game or suggesting a statin for secondary prevention, little plays can add up significantly over time. We need to make the most of every situation.

Attention to Detail: Whether counting players on the field or noticing trends in potassium levels, paying attention to detail is vitally important.

Pride, Passion, and Inspiration: The Rider Nation can make a difference to players' morale with hats made of real watermelons, green Rider jerseys, a 6-foot gopher, flags, and face paint. In pharmacy, with all of us supporting and advocating for our profession by showing our "professional colours", we can make a difference to our profession and our patients!

As I anticipate what lies ahead for our profession, I am overcome with excitement. Perhaps the dawn of a "Pharmacist Nation" is on the horizon. I wonder . . . what food should we wear on our heads?

Jason Howorko, BSP, BSC, ACPR, is President and External Liaison for the CSHP. 